\title{
Race 3, a New and Highly Virulent Race of Fusarium oxysporum f. sp. niveum Causing Fusarium Wilt in Watermelon
}

X. G. Zhou, Texas A\&M University System, AgriLife Research and Extension Center, Beaumont 77713; K. L. Everts, University of Maryland, Lower Eastern Shore Research and Education Center, and University of Delaware, Georgetown 19947; and B. D. Bruton, United States Department of Agriculture-Agricultural Research Service, South Center Agricultural Research Laboratory, Lane, OK 74555

\begin{abstract}
Zhou, X. G., Everts, K. L., and Bruton, B. D. 2010. Race 3, a new and highly virulent race of Fusarium oxysporum f. sp. niveum causing Fusarium wilt in watermelon. Plant Dis. 94:92-98.

Three races $(0,1$, and 2$)$ of Fusarium oxysporum $\mathrm{f}$. sp. niveum have been previously described in watermelon (Citrullus lanatus) based on their ability to cause disease on differential watermelon genotypes. Four isolates of $F$. oxysporum $\mathrm{f}$. sp. niveum collected from wilted watermelon plants or infested soil in Maryland, along with reference isolates of races 0,1 , and 2, were compared for virulence, host range, and vegetative compatibility. Race identification was made on the watermelon differentials Sugar Baby, Charleston Gray, Dixielee, Calhoun Gray, and PI-296341$F R$ using a root-dip, tray-dip, or pipette inoculation method. All four Maryland isolates were highly virulent, causing 78 to $100 \%$ wilt on all differentials, one of which was PI-296341-FR, considered highly resistant to race 2 . The isolates also produced significantly greater colonization in the lower stems of PI-296341-FR than a standard race 2 reference isolate. In field microplots, two of the isolates caused over $90 \%$ wilt on PI-296341-FR, whereas no disease was caused by a race 2 isolate. All four isolates were nonpathogenic on muskmelon, cucumber, pumpkin, and squash, confirming their host specific pathogenicity to watermelon. The Maryland isolates were vegetatively compatible to each other but not compatible with the race 2 isolates evaluated, indicating their genetic difference from race 2 . This study proposes that the Maryland isolates belong to a new race, race 3 , the most virulent race of $F$. oxysporum $\mathrm{f}$. sp. niveum described to date.
\end{abstract}

Fusarium oxysporum f. sp. niveum (E.F. Sm.) W.C. Snyder \& H.N. Han., the casual agent of Fusarium wilt of watermelon (Citrullus lanatus (Thunb.) Matsum. \& Nakai), is widespread in watermelongrowing regions of the world, and frequently is the major factor limiting triploid (seedless) watermelon production. In the United States, the disease was first described by Smith in 1894 in South Carolina and Georgia (33). F. oxysporum f. sp. niveum is host specific and causes disease only on watermelon, although a few exceptions have been reported in studies conducted under greenhouse conditions $(21,40)$.

Differences in virulence among isolates of $F$. oxysporum $\mathrm{f}$. sp. niveum have long been recognized $(25,30)$ and isolates are

Corresponding author: K. L. Everts

E-mail: keverts@umd.edu

Former address of X. G. Zhou: Lower Eastern Shore Research and Education Center, Salisbury, MD 21801.

Accepted for publication 18 September 2009.

doi:10.1094/PDIS-94-1-0092

This article is in the public domain and not copyrightable. It may be freely reprinted with customary crediting of the source. The American Phytopathological Society, 2010. subdivided into three races on the basis of virulence on watermelon cultivars that vary in their level of resistance $(2,6,21,27,37)$. In 1963, Crall (8) described two physiological races of $F$. oxysporum f. sp. niveum in Florida according to virulence on cultivars such as Florida Giant (susceptible), Charleston Gray (moderately resistant), and Summit (highly resistant) but did not provide a race designation. In 1972, Cirulli (6) also differentiated two races in Italy and designated them as race 0 and race 1 according to disease reactions on Sugar Baby (susceptible), Charleston Gray, and Calhoun Gray (highly resistant). Race 0 caused wilt only on the susceptible cultivar, while race 1 caused wilt on cultivars classified as moderately resistant to Fusarium wilt. In 1973, Netzer and Dishon (28) reported a highly aggressive isolate and classified it as a new race. The race was virulent toward race-1-resistant cultivars such as Calhoun Gray, Summit, and Smokylee $(27,28)$. They designated this isolate as race 2 following the numbering system of Cirulli (6). In 1985, Martyn (19) reported two isolates of race 2 from Texas, both of which caused severe wilt in all known resistant commercial watermelon cultivars (20). Since then, race 2 was reported in Oklahoma in 1988 (5), in Florida in 1989 (22), and in Maryland and Delaware in 2001 (36). In 2003, Zhou and
Everts (37) reported that race 2 was widely distributed in Maryland and Delaware, present in $22 \%$ of the watermelon production fields surveyed. More recently, race 2 was found in Georgia (3), Indiana (10), and South Carolina (A. P. Keinath, personal communication). Race 2 also has been reported in China (9) and in the eastern Mediterranean region, including $\mathrm{Cy}$ prus (14), Greece (27), Spain (11), and Turkey (27).

Martyn and Netzer (24) proposed inclusion of PI-296341-FR (C. lanatus var. citroides) as a differential for classifying races of $F$. oxysporum f. sp. niveum, along with Sugar Baby, Charleston Gray, and Calhoun Gray (Table 1). By their system, race 0 causes wilt only on Sugar Baby; race 1 causes wilt on Sugar Baby and Charleston Gray but not on Calhoun Gray and PI-296341-FR; and race 2 causes wilt on all differentials except PI-296341-FR. Therefore, PI-296341-FR is the key to differentiating any new and more virulent race of $F$. oxysporum f. sp. niveum from race 2 .

However, difficulties in differentiating races of $F$. oxysporum f. sp. niveum have been encountered in some previous studies $(1,17,22)$. This is because races of $F$. oxysporum $\mathrm{f}$. sp. niveum are not defined as clearly as in many other formae speciales of $F$. oxysporum, where races are based on a gene-for-gene relationship on differential cultivars $(17,31)$. Therefore, races within $F$. oxysporum f. sp. niveum were differenti-

Table 1. Disease reaction of watermelon genotypes used to differentiate races of Fusarium oxysporum f. sp. niveum ${ }^{\mathrm{y}}$

\begin{tabular}{lllll}
\hline & \multicolumn{4}{c}{ Race $^{\mathbf{z}}$} \\
\cline { 2 - 5 } Genotype & $\mathbf{0}$ & $\mathbf{1}$ & $\mathbf{2}$ & $\mathbf{3}$ \\
\hline Sugar Baby & $\mathrm{S}$ & $\mathrm{S}$ & $\mathrm{S}$ & $\mathrm{S}$ \\
Charleston Gray & $\mathrm{R}$ & $\mathrm{S}$ & $\mathrm{S}$ & $\mathrm{S}$ \\
Calhoun Gray & $\mathrm{R}$ & $\mathrm{R}$ & $\mathrm{S}$ & $\mathrm{S}$ \\
PI-296341-FR & $\mathrm{R}$ & $\mathrm{R}$ & $\mathrm{R}$ & $\mathrm{S}$ \\
\hline
\end{tabular}

y Race classification system is developed from Cirulli (6), Netzer (27), Martyn (21), Martyn and Netzer (24), and Zhou et al. (42).

${ }^{\mathrm{z}}$ Assignments of disease reaction ratings are based on incidence of Fusarium wilt on the differential genotypes, where $\mathrm{R}=$ resistant ( $<33 \%$ wilt) and $\mathrm{S}=$ susceptible ( $\geq 33 \%$ wilt), following the criteria established by Martyn and Bruton (22) and used by other studies $(9,37)$. 
ated according to variability in aggressiveness on differential cultivars rather than discrete susceptible or resistant reactions. This led some investigations to conclude that no distinct races within $F$. oxysporum f. sp. niveum could be clearly identified $(1,25,30,32)$. They suggested that differences among races were primarily due to differences in the level of aggressiveness, not virulence on differential cultivars $(8,17,21)$. However, race classification that is based on degree of virulence rather than aggressiveness can be determined by strict adherence to specific assay methods. For example, because of variation in aggressiveness that is observed in some experiments, there is speculation that races 0 and 1 are a single race $(1,17,21)$. However, the distinction between races 0 or 1 and race 2 has not been challenged because race 2 exhibits a significantly higher level of virulence on differential cultivars such as Calhoun Gray and Dixielee.

In addition to pathogenicity, vegetative compatibility has been used as a collaborative method to characterize isolates within the formae species of $F$. oxysporum $\mathrm{f}$. sp. niveum $(17,40)$ and to distinguish race 2 populations of $F$. oxysporum f. sp. niveum from race 1 in a soil population biology study (13). Currently, no molecular techniques have been developed to effectively differentiate races of $F$. oxysporum $\mathrm{f}$. sp. niveum, although analyses of restriction fragment length polymorphism (RFLP) and amplified fragment length polymorphism (AFLP) were studied previously $(9,15)$.

In an initial pathogenicity test, four isolates of $F$. oxysporum f. sp. niveum collected by Zhou and Everts from Maryland were highly virulent toward PI-296341$F R$. The objectives of this study were to further characterize these four Maryland isolates by pathogenicity in greenhouse and field microplots, examine their host range and vegetative compatibility, and determine whether they were different from race 2 and could be classified as a new race. A brief report of this study has been published (42).

\section{MATERIALS AND METHODS}

Source of isolates. Eleven isolates of $F$. oxysporum $\mathrm{f}$. $\mathrm{sp}$. niveum were used in this study (Table 2). In 2000, MD-ZE085 was isolated from the stem of a wilted watermelon plant collected from a commercial watermelon production field in Wicomico County in Maryland, where severe Fusarium wilt occurred. MD-ZE125 was isolated from a soil sample collected from a highly infested field on a research farm in Wicomico County, MD. In 2007, two additional isolates, MD-ZE622 and MDZE632, were isolated from stems of wilted watermelon plants in commercial watermelon fields in Wicomico and Dorchester Counties in Maryland. All four isolates were collected from colonies on K's Fusa- rium-selective medium (16), single-spore cultured, and stored in soil tubes at $4^{\circ} \mathrm{C}$. Identification of $F$. oxysporum f. sp. niveum was according to fungal morphology (26) and pathogenicity of each isolate on the wilt-susceptible watermelon cv. Sugar Baby. Seven isolates that were previously categorized to race (one race 1 , one race 0 , and five race 2) (Table 1) were included as reference isolates in this study. ATCC-44293 and TX-X1D were purchased from the American Type Culture Collection (ATCC), Manassas, VA.

Inoculum preparation. To prepare inoculum, colonized agar plugs $(2 \mathrm{~mm}$ in diameter) from a 7- to 10-day-old colony on potato-dextrose agar (PDA) were transferred into a liquid mineral salt medium (27) and grown for 10 to 14 days on a rotary shaker at $128 \mathrm{rpm}$ at room temperature. Colonized liquid medium was filtered through four layers of sterile cheesecloth and the suspension of spores (>95\% microconidial) was adjusted to approximately $1 \times 10^{6}$ microconidia/ml using a hemacytometer.

Greenhouse pathogenicity test. Three methods were used to inoculate seedlings of watermelon in separate experiments. The first method was the standard root dip $(18,20)$. At the first true leaf stage, seedlings raised in soilless potting mix consisting of vermiculite-peat moss $(2: 3, \mathrm{vol} / \mathrm{vol})$ (Redi-Earth, Scotts-Sierra Inc., Marysville, $\mathrm{OH})$ were uprooted and the roots washed gently in water. Seedling roots were dipped into an inoculum for $30 \mathrm{~s}$ and transplanted into plastic pots ( 10 by 10 by $8 \mathrm{~cm}$ ) filled with the same soilless potting mix with 10 plants per pot. The second method was tray-dip inoculation $(18,22)$. Seed were sown in plastic trays with cells ( 3 by 3 by $5 \mathrm{~cm}, 128$ cells/tray) containing the soilless potting mix described above and then placed inside a larger plastic flat filled with the same potting mix. After emergence, seedlings were thinned to one plant per cell. At the first true leaf stage, at which time the roots of the seedlings had grown through the drainage holes of the trays and into the potting mix in the larger flat, the trays were lifted and rinsed briefly with water. The roots of the seedlings were uniformly trimmed to about $3 \mathrm{~cm}$. The entire tray was placed in a shallow plastic flat filled with $300 \mathrm{ml}$ of spore suspension of the inoculum for $20 \mathrm{~min}$ and then returned to the original larger flat. The third method was the pipette inoculation technique (18). Seedlings were raised in the potting mix in plastic pots ( 6 by 6 by 5 $\mathrm{cm}$ ) of 10 plants each. At the first true leaf stage, $3 \mathrm{ml}$ of inoculum was delivered to the potting mix around each seedling with a pipette (Labsystems, Helsinki, Finland).

Race was identified based on the reaction of the following differentials recommended by previous studies $(2,17,20$ 22,37): Sugar Baby, Charleston Gray, Dixielee, Calhoun Gray, PI-296341-FR (FL), PI-296341-FR (OK), and PI-296341-FR (MD). Two sources of PI-296341-FR, which were originally released in 1991 by R. D. Martyn and D. Netzer (24), were included. They were provided by B. Carle in Florida in 1999 and by B. D. Bruton in Oklahoma in 2004 as PI-296341-FR (FL) and PI-296341-FR (OK), respectively. Two sources of PI-296341-FR were included because segregation for susceptibility to race 2 was observed in progeny of the FL and OK increases of PI-296341-FR to produce the seed used in our initial tests. To improve race 2 resistance in the PI lines, a third PI line, designated as PI296341-FR (MD), was developed at the University of Maryland Lower Eastern Shore Research and Education Center in Salisbury by inoculating seedlings of PI296341-FR (FL) and PI-296341-FR (OK) with two race 2 isolates of $F$. oxysporum $\mathrm{f}$. sp. niveum in a greenhouse, transplanting the surviving plants into a field naturally infested with a mixture of races 1 and 2 , and harvesting seed from watermelon fruit on plants with no sign of Fusarium wilt. All other watermelon cultivars were obtained from commercial seed suppliers.

Three evaluations to determine level of virulence of the Maryland isolates were conducted. The first evaluation was done in 2002 using all three inoculation methods

Table 2. Isolates of Fusarium oxysporum f. sp. niveum used as standard references and for race determination $^{\mathrm{y}}$

\begin{tabular}{lcllccl}
\hline & & \multicolumn{2}{c}{ Geographic origin } & & \\
\cline { 7 - 7 } Isolate & Race & Source & County & State $^{\mathbf{z}}$ & Year & \multicolumn{1}{c}{ Provider (reference) } \\
\hline TX-471 & 0 & $\ldots$ & $\ldots$ & TX & $\ldots$ & Bruton, B. D \\
ATCC-44293 & 1 & Plant & $\ldots$ & CA & $\ldots$ & Netzer, D (27) \\
TX-X1D & 2 & Stem & Frio & TX & 1981 & Martyn, R. D. (20) \\
F-032-1 & 2 & Stem & Wicomico & MD & 2000 & Zhou, X. G. \& Everts, K. L. (37) \\
F-100-2 & 2 & Stem & Sussex & DE & 2000 & Zhou, X. G. \& Everts, K. L.(37) \\
F-17B-R-2 & 2 & Root & Wicomico & MD & 2000 & Zhou, X. G. \& Everts, K. L.(37) \\
F-17B-1-10 & 2 & Soil & Wicomico & MD & 1999 & Zhou, X. G. \& Everts, K. L.(37) \\
MD-ZE085 & 3 & Stem & Wicomico & MD & 2000 & Zhou, X. G. \& Everts, K. L. \\
MD-ZE125 & 3 & Soil & Wicomico & MD & 2000 & Zhou, X. G. \& Everts, K. L. \\
MD-ZE622 & 3 & Stem & Wicomico & MD & 2007 & Zhou, X. G. \& Everts, K. L. \\
MD-ZE632 & 3 & Stem & Dorchester & MD & 2007 & Zhou, X. G. \& Everts, K. L. \\
\hline
\end{tabular}

${ }^{y}$ Symbol: $\ldots=$ not available.

${ }^{\mathrm{z}} \mathrm{CA}=$ California, $\mathrm{DE}=$ Delaware, $\mathrm{MD}=$ Maryland, and $\mathrm{TX}=$ Texas. 
for the two Maryland isolates (MD-ZE085 and MD-ZE125) on the FL increase of the PI line, PI-296341-FR (FL). The second evaluation was conducted in 2005 using only the standard root-dip method, in which the second PI line PI-296341-FR (OK) was included for comparison with PI-296341-FR (FL) and an additional assessment for colonization by $F$. oxysporum f. sp. niveum in lower stems of inoculated plants also was made for selected genotypes. Stem colonization was determined based on the procedure described previously (38). At the conclusion of the greenhouse experiment, three plants per replicate were randomly selected from the remaining live plants, and their lower stem sections $(5 \mathrm{~cm}$ in length starting at the soil line) were collected. The stem sections were washed in tap water, surface disinfected with $0.6 \% \mathrm{NaOCl}$ for $1 \mathrm{~min}$, and rinsed in tap water four times. The stem samples were further cut into short pieces (about $10 \mathrm{~mm}$ long), weighed, and homogenized in sterile water in a blender. The resulting suspensions were filtered through four layers of sterilized cheesecloth and the filtered suspensions were pipetted onto K's medium for culturing Fusarium colonies. After 7 to 10 days at room temperature, colonies on plates were counted and counts converted into CFU per gram of fresh tissue. There were three plates for each of three replicates.

In 2008, the root-dip method was used to evaluate the reaction of Sugar Baby, Charleston Gray, and Calhoun Gray along with the improved race 2 resistant PI line PI-296341-FR (MD). Two additional Maryland isolates (MD-ZE622 and MDZE632), obtained in 2007, were included along with four more race-2 isolates (F032-1, F-100-2, F-17B-R-2, and F-17B1$10)$ of $F$. oxysporum $\mathrm{f}$. sp. niveum for a total of five race 2 reference isolates tested.

In each experiment, each combination of genotype and isolate was represented by three replicate pots, with 10 plants per pot. Water-inoculated plants for each genotype were included as the controls. Seedlings in all experiments were maintained in a greenhouse with the temperature ranging from 19 to $28^{\circ} \mathrm{C}$. After inoculation, the percentage of seedlings showing typical symptoms of Fusarium wilt (yellowing, stunting, or wilting) was assessed weekly and the percentage of wilt or death at 4 weeks after inoculation was recorded. To compare disease reactions for each genotype and isolate treatment, a genotype giving mean wilt incidence of $\geq 33 \%$ was considered susceptible and $<33 \%$ was considered resistant (Table 1). This rating criterion followed the system established by Martyn and Bruton (22), which was later used in other studies for race determination of $F$. oxysporum f. sp. niveum $(9,37)$. Each experiment was conducted twice.

Field microplot test. Two Maryland isolates, MD-ZE085 and MD-ZE125, were further evaluated for virulence on the two watermelon differentials Calhoun Gray and PI-296341-FR (MD) in field microplots during summer 2008. A third isolate with known race 2 designation (F-1002) was also included for comparison. The Norfolk "A" loamy sand soil ( $\mathrm{pH}$ 6.3) used in microplots $(76 \mathrm{~cm}$ in diameter and 61 $\mathrm{cm}$ deep, surrounded by fiber glass) was fumigated with metam-potassium (K-pam II) at approximately $42 \mathrm{ml} / \mathrm{m}^{2}$ under black plastic film. The film was removed after 4 days, and the plots were aerated by turning the soil with a rake twice a week for 4 weeks prior to incorporating inoculum. Inoculum for each isolate was prepared as described earlier and added to the top 20 $\mathrm{cm}$ of soil. After 4 weeks, when inoculum density in the soil stabilized at approximately 6,500 CFU/g soil as determined by plating diluted soil on K's medium, five 4week-old plants of Calhoun Gray were transplanted in one half of each microplot, and the other half was transplanted with five 4-week-old plants of PI-296341-FR (MD). Microplots not infested with either isolate served as controls. Four replicate microplots for each isolate-genotype combination were arranged in a randomized complete block design. A repeat of this experiment was initiated 2 weeks after transplants were placed into the first set of microplots. The second experiment was conducted in a second set of microplots that were located within the same field The percentage of plants showing symptoms of Fusarium wilt (yellowing, stunting, and/or wilting) was assessed and recorded at 6 weeks after transplanting. Transplant dates for the first and second experiment were 1 and 14 June 2008, respectively. Average air temperature, maximum temperature, and minimum temperature during the 6 -week study period were $23.9,36.1$, and $17.6^{\circ} \mathrm{C}$ for the first experiment and 23.6, 33.7, and $10.6^{\circ} \mathrm{C}$, respectively, for the second experiment.

Host range test. In all, 19 cultivars representing seven plant species, including 16 cultivars within two genera of Cucurbitaceae (excluding Citrullus spp.), were tested for susceptibility to all the 11 isolates of $F$. oxysporum f. sp. niveum in the greenhouse. These were 10 muskmelon (Cucumis melo L.) cultivars (Ananas, Honeydew Greenflesh, Honeydew Orangeflesh, Imperial 4-50, Israeli [Old Original], Planter's Jumbo, Super Star, Tam-Dew [Honey Dew], Top Mark, and Yellow Canary), two cucumber (C. sativus L.) cultivars (Vlaspik and Orient Express), two squash (Cucurbita spp.) cultivars (Zucchini Elite and Goldbar), two pumpkin (Cucurbita pepo L.) cultivars (Wizard and Magic Lantern), a tomato (Lycopersicon esculentum Mill.) cultivar (Campbell 1327FR), a spinach (Spinacia oleracea L.) cultivar (Seven R), and a corn (Zea mays L.) cultivar (Bonus). The wilt-susceptible watermelon cv. Sugar Baby was included as a positive control. Water-inoculated plants were included as a negative control. Inoculations were conducted at 2 to 3 weeks after seeding, when most plants reached the first true leaf stage, using the same root-dip inoculation procedure as described before. Each combination of cultivar and isolate had three replicate pots (10 by 10 by $8 \mathrm{~cm}$ ) filled with the same soilless potting mix as described before, and each pot contained 10 seedlings. The plants were maintained in a greenhouse with temperatures ranging from 18 to $30^{\circ} \mathrm{C}$. Inoculum preparation and disease assessment were the same as greenhouse pathogenicity tests. The experiment was conducted twice.

Vegetative compatibility test. Vegetative compatibility tests were performed following the method developed by $\mathrm{Pu}$ halla (29) and Correll et al. (7). Nitrate nonutilizing (nit) mutants were generated on both minimal salts medium (MM) and PDA containing $1.5 \% \mathrm{KClO}_{3}$. Portions of the fast-growing sectors emerging from restricted colonies were transferred to both MM and PDA. Those that produced thin, expansive growth with no aerial mycelium on MM but showed wild-type growth with aerial mycelium on PDA were considered to be nit mutants. The nit mutants were generated from each isolate until two complementary nit mutants were obtained. Complementary mutants were recognized by the robust growth at the interface of the two colonies (a visual indication of heterokaryon formation) when paired on MM under a daily 12-h fluorescent light for 5 to 14 days at 22 to $25^{\circ} \mathrm{C}$. Mutants generated from each isolate were characterized as one of three physiological phenotypes (nit1, NitM, and nit3) on the basis of growth on MM supplemented with different nitrogen sources (7). In all, 6 to 10 mutants were recovered from each isolate, and three nit mutants (nit1, NitM and nit3) from each isolate were chosen as testers. The testers of each isolate were paired in all combinations with testers of other isolates. If a mutant from one isolate formed a heterokaryon with at least one of the three testers of another isolate, both isolates were considered compatible and placed in the same vegetative compatible group. Each pairing in all combinations with vegetative compatibility group testers was conducted at least three times.

Data analysis. All statistical analyses were conducted using the SAS software package (version 8.2; SAS Institute Inc., Cary, NC). Analysis of variance was performed on data with the general linear model procedure. Means for treatments were compared using Fisher's protected least significant difference at $P=0.05$. Disease incidence data were arcsine-square root transformed and $\mathrm{CFU} / \mathrm{g}$ data transformed into $\log _{10}(\mathrm{CFU} / \mathrm{g}+1)$ for analysis. The results of two repeated experiments were combined for presentation if no sig- 
nificant experiment-treatment interactions were present. The linear regression procedure of SAS was performed to characterize the relationships among stem tissue colonization and incidence of Fusarium wilt.

\section{RESULTS}

Greenhouse pathogenicity test. In the first evaluation conducted in 2002, the use of the root-dip, tray-dip, and pipette inoculation methods resulted in similar results (Table 3). The two Maryland isolates, MDZE085 and MD-ZE125, were highly virulent and caused more than $78 \%$ wilt on all five differentials tested, including PI296341-FR (FL) that is considered resistant to race 2 . In contrast, the race 2 reference isolate TX-X1D produced a high incidence of wilt $(\geq 67 \%)$ only on Sugar Baby, Charleston Gray, Dixielee, and Calhoun Gray but not on PI-296341-FR (FL). Both Maryland isolates caused susceptible reactions on PI-296341-FR (FL) whereas TX-X1D caused resistant reactions (Table 3). The small amount of wilt showing on the PI genotype inoculated with TX-X1D resulted from the small percentage of plants segregating to a race-2-susceptible phenotype. The reference isolates of races 0 (TX-471) and 1 (ATCC-44293) produced expected disease reactions. TX-471 caused severe wilt on Sugar Baby but was avirulent to all other genotypes possessing wiltresistant genes; ATCC-44293 produced a high level of wilt on Sugar Baby, a moderate level of wilt on Charleston Gary, and little or no disease on all other differentials.

In 2005, a similar evaluation was conducted in which a second source of the PI differential, PI-296341-FR (OK), was included for comparisons with PI-296341$F R$ (FL). In this test, colonization by $F$. oxysporum f. sp. niveum in lower stems of inoculated plants also was determined in the Dixielee, Calhoun Gray, and both PI lines, which are resistant to races 0 and 1 . The two Maryland isolates produced comparably high levels of wilt and stem colonization on all genotypes tested, including both PI-296341-FR (FL) and PI-296341$F R(\mathrm{OK})$ (Table 4). At 4 weeks post inoculation, both Maryland isolates produced high incidence of wilt in excess of $97 \%$ on PI-296341-FR (FL) and PI-296341-FR (OK). However, these two PI lines were resistant to TX-X1D, which induced wilt in less than $33 \%$ of the tested plants. The two Maryland isolates colonized stems of both PI lines to a significantly greater extent than TX-X1D. There were no significant $(P>0.05)$ differences between the Maryland isolates and TX-X1D in wilt incidence and stem colonization on all other differentials except on Dixielee, where Maryland isolates caused more stem colonization than TX-X1D. When regression analysis was made over all isolates and genotypes (Table 4), incidence of Fusarium wilt ( $Y$, percent wilt) was strongly correlated to stem colonization $(X$, $\mathrm{CFU} / \mathrm{g}$ tissue), with the regression equation of $Y=37.35 \log _{10}(X+1)-7.15\left(R^{2}\right.$ adj. $=0.90, P<0.0001)$. The results of the evaluations conducted in 2002 and 2005

Table 3. Incidence of Fusarium wilt of five differential watermelon genotypes and disease reaction ratings on PI-296341-FR (FL) inoculated with isolates of Fusarium oxysporum f. sp. niveum using root-dip, tray-dip, and pipette methods in 2002

\begin{tabular}{|c|c|c|c|c|c|c|}
\hline \multirow[b]{2}{*}{ Inoculation method, isolate } & \multicolumn{5}{|c|}{ Wilt on watermelon genotype $(\%)^{y}$} & \multirow[b]{2}{*}{ Reaction $^{\mathrm{z}}$} \\
\hline & Sugar Baby & Charleston Gray & Dixielee & Calhoun Gray & PI-296341-FR (FL) & \\
\hline \multicolumn{7}{|l|}{ Root-dip } \\
\hline TX-471 & $100 \mathrm{~b}$ & $7 \mathrm{a}$ & $0 \mathrm{a}$ & $0 \mathrm{a}$ & $5 \mathrm{a}$ & $\mathrm{R}$ \\
\hline ATCC-44293 & $92 \mathrm{a}$ & $67 \mathrm{~b}$ & $0 \mathrm{a}$ & $0 \mathrm{a}$ & $0 \mathrm{a}$ & $\mathrm{R}$ \\
\hline TX-X1D & $100 \mathrm{~b}$ & $97 \mathrm{c}$ & $97 \mathrm{~b}$ & $92 \mathrm{~b}$ & $30 \mathrm{~b}$ & $\mathrm{R}$ \\
\hline MD-ZE085 & $98 \mathrm{~b}$ & $100 \mathrm{c}$ & $100 \mathrm{c}$ & $100 \mathrm{c}$ & $98 \mathrm{~d}$ & $\mathrm{~S}$ \\
\hline MD-ZE125 & $100 \mathrm{~b}$ & $100 \mathrm{c}$ & $100 \mathrm{c}$ & $97 \mathrm{bc}$ & $92 \mathrm{c}$ & $\mathrm{S}$ \\
\hline \multicolumn{7}{|l|}{ Tray-dip } \\
\hline TX-471 & $73 \mathrm{a}$ & $7 \mathrm{a}$ & $0 \mathrm{a}$ & $0 \mathrm{a}$ & $0 \mathrm{a}$ & $\mathrm{R}$ \\
\hline ATCC-44293 & $77 \mathrm{ab}$ & $68 \mathrm{~b}$ & $1 \mathrm{a}$ & $4 \mathrm{a}$ & $7 \mathrm{~b}$ & $\mathrm{R}$ \\
\hline TX-X1D & $89 \mathrm{bc}$ & $86 \mathrm{bc}$ & $67 \mathrm{~b}$ & $68 \mathrm{~b}$ & $20 \mathrm{c}$ & $\mathrm{R}$ \\
\hline MD-ZE085 & $100 \mathrm{c}$ & $92 \mathrm{c}$ & $82 \mathrm{c}$ & $80 \mathrm{c}$ & $81 \mathrm{~d}$ & $\mathrm{~S}$ \\
\hline MD-ZE125 & $99 \mathrm{c}$ & $92 \mathrm{c}$ & $91 \mathrm{~d}$ & $92 \mathrm{~d}$ & $86 \mathrm{~d}$ & $\mathrm{~S}$ \\
\hline \multicolumn{7}{|l|}{ Pipette } \\
\hline TX-471 & $78 \mathrm{a}$ & $5 \mathrm{a}$ & $0 \mathrm{a}$ & $0 \mathrm{a}$ & $0 \mathrm{a}$ & $\mathrm{R}$ \\
\hline ATCC-44293 & $78 \mathrm{a}$ & $50 \mathrm{~b}$ & $0 \mathrm{a}$ & $0 \mathrm{a}$ & $0 \mathrm{a}$ & $\mathrm{R}$ \\
\hline TX-X1D & $100 \mathrm{~b}$ & $95 \mathrm{c}$ & $85 \mathrm{~b}$ & $80 \mathrm{~b}$ & $22 \mathrm{~b}$ & $\mathrm{R}$ \\
\hline MD-ZE085 & $100 \mathrm{~b}$ & $100 \mathrm{c}$ & $95 \mathrm{c}$ & $92 \mathrm{c}$ & $97 \mathrm{~d}$ & $\mathrm{~S}$ \\
\hline MD-ZE125 & $100 \mathrm{~b}$ & $100 \mathrm{c}$ & $97 \mathrm{c}$ & $92 \mathrm{c}$ & $78 \mathrm{c}$ & S \\
\hline
\end{tabular}

y Data were averaged over two experiments of three replicated pots or trays (10 plants/pot or tray) each. Incidence of Fusarium wilt was rated at 4 weeks after inoculation. Means in column under each inoculation method followed by the same letter are not significantly different $(P=0.05)$ according to Fisher's protected least significant difference test. Wilt incidence data were arcsine-square root transformed prior to analysis.

${ }^{\mathrm{z}}$ Ratings of disease reaction on PI-296341-FR (FL) were assigned for the isolates based on incidence of Fusarium wilt on the differential genotype, where R $=$ resistant $(<33 \%$ wilt $)$ and $\mathrm{S}=$ susceptible ( $\geq 33 \%$ wilt), following the criteria established by Martyn and Bruton (22).

Table 4. Incidence of Fusarium wilt and stem colonization of six differential watermelon genotypes and disease reaction ratings on the FL and OK increases of PI-296341-FR inoculated with isolates of Fusarium oxysporum f. sp. niveum using the root-dip method in $2005^{y}$

\begin{tabular}{|c|c|c|c|c|c|c|c|c|c|c|c|c|c|}
\hline \multirow[b]{2}{*}{ Isolate } & \multicolumn{2}{|c|}{ Sugar Baby } & \multicolumn{2}{|c|}{ Charleston Gray } & \multicolumn{2}{|c|}{ Dixielee } & \multicolumn{2}{|c|}{ Calhoun Gray } & \multicolumn{2}{|c|}{ PI-296341-FR(FL) } & \multicolumn{2}{|c|}{ PI-296341-FR(OK) } & \multirow[b]{2}{*}{ Reaction $^{\mathrm{z}}$} \\
\hline & Wilt (\%) & Stem & Wilt (\%) & Stem & Wilt (\%) & Stem & Wilt (\%) & Stem & Wilt (\%) & Stem & Wilt (\%) & Stem & \\
\hline TX-471 & $90 \mathrm{a}$ & $\ldots$ & $18 \mathrm{a}$ & $\ldots$ & $0 \mathrm{a}$ & $0 \mathrm{a}$ & $0 \mathrm{a}$ & $0 \mathrm{a}$ & $3 \mathrm{a}$ & $0 \mathrm{a}$ & $5 \mathrm{a}$ & $0 \mathrm{a}$ & $\mathrm{R}$ \\
\hline ATCC-44293 & $100 \mathrm{~b}$ & $\ldots$ & $100 \mathrm{~b}$ & $\ldots$ & $5 \mathrm{a}$ & $3 \mathrm{a}$ & $0 \mathrm{a}$ & $10 \mathrm{~b}$ & $5 \mathrm{a}$ & $0 \mathrm{a}$ & $15 \mathrm{bc}$ & $6 \mathrm{a}$ & $\mathrm{R}$ \\
\hline TX-X1D & $100 \mathrm{~b}$ & $\ldots$ & $100 \mathrm{~b}$ & $\ldots$ & $98 \mathrm{c}$ & $321 \mathrm{~b}$ & $97 \mathrm{~b}$ & $427 \mathrm{c}$ & $25 \mathrm{~b}$ & $35 \mathrm{~b}$ & $32 \mathrm{c}$ & $38 \mathrm{~b}$ & $\mathrm{R}$ \\
\hline MD-ZE085 & $100 \mathrm{~b}$ & $\ldots$ & $100 \mathrm{~b}$ & $\ldots$ & $100 \mathrm{c}$ & $1067 \mathrm{c}$ & $98 \mathrm{~b}$ & $477 \mathrm{c}$ & $97 \mathrm{c}$ & $293 \mathrm{c}$ & $98 \mathrm{~d}$ & $291 \mathrm{c}$ & $\mathrm{S}$ \\
\hline MD-ZE125 & $100 \mathrm{~b}$ & $\ldots$ & $100 \mathrm{~b}$ & $\ldots$ & $100 \mathrm{c}$ & $806 \mathrm{c}$ & $97 \mathrm{~b}$ & $674 \mathrm{c}$ & $97 \mathrm{c}$ & $343 \mathrm{c}$ & $100 \mathrm{~d}$ & $691 \mathrm{c}$ & $\mathrm{S}$ \\
\hline
\end{tabular}

${ }^{y}$ Data were averaged over two experiments of three replicated pots (10 plants/pot) each. Incidence of Fusarium wilt was rated at 4 weeks after inoculation. Stem colonization (CFU/g fresh tissue) by F. oxysporum f. sp. niveum was assayed at the conclusion of the experiments by placing serially diluted, homogenized lower stem tissues on K's medium (16). Means in column followed by the same letter are not significantly different $(P=0.05)$ according to Fisher's protected least significant difference test. Prior to analysis, wilt incidence and CFU data were arcsine-square root- and log 10 (CFU/g +1$)$-transformed, respectively; $\ldots=$ not assayed.

${ }^{\mathrm{z}}$ Ratings of disease reaction on PI-296341-FR (FL) or PI-296341-FR (OK) were assigned for the isolates based on mean wilt incidence on the two differential genotypes, where $\mathrm{R}=$ resistant ( $<33 \%$ wilt) and $\mathrm{S}=$ susceptible ( $\geq 33 \%$ wilt), following the criteria established by Martyn and Bruton ( 22$)$. 
with the two Maryland isolates provided the first indication of a possible new, more aggressive race.

In 2008, a third evaluation was conducted using the PI line PI-296341-FR (MD) that had been selected and developed for improved race 2 resistance. Two additional Maryland isolates, MD-ZE622 and MDZE632, obtained in 2007, were also included (Table 5). There was a clear difference between the four Maryland isolates and the five race 2 reference isolates based on disease reaction ratings on PI-296341-FR (MD). Inoculations with the Maryland isolates resulted in equally severe levels of wilt (over 95\%) on the genotype while inoculations with the five race 2 isolates produced little or no disease. All four Maryland isolates had identical disease reaction and were capable of causing substantial wilt (over 98\%) on Sugar Baby, Charleston Gray, and Calhoun Gray. The five race 2 isolates reacted similarly and produced comparably severe levels of wilt on these differential cultivars. No disease was produced from inoculations with either TX-471 (race 0) or ATCC-44293 (race 1) on PI-296341-FR (MD) or Calhoun Gray. These results clearly demonstrated that the four new Maryland isolates were a distinct group and separate from race 2 isolates and races 0 and 1 isolates on the basis of disease reactions on PI-296341-FR (MD).

Field microplot test. In both experiments, MD-ZE085 and MD-ZE125 produced high incidence of wilt (over 90\%) on PI-296341-FR (MD) whereas the race-2 reference isolate F-100-2 caused no disease on PI-296341-FR (MD) (Table 6). All three isolates caused disease in Calhoun Gray, with the incidence of wilt ranging from 95 to $100 \%$.

Host range test. None of the 16 cultivars (non-Citrullus spp.) within Cucurbitaceae inoculated with any of the four Maryland isolates developed symptoms of Fusarium wilt (data not shown). The nonCitrullus cultivars included those from four species of Cucurbitaceae: cucumber, muskmelon, pumpkin, and squash. In contrast, the four new Maryland isolates were capable of causing $100 \%$ wilt on the watermelon cv. Sugar Baby. No disease was observed on tomato, corn, or spinach inoculated with the Maryland isolates.

Vegetative compatibility test. All isolates used in the present study were self compatible. The four new Maryland isolates were vegetatively compatible with each other but all were incompatible with the reference isolates of races 0,1 , and 2 evaluated.

\section{DISCUSSION}

Three races $(0,1$, and 2$)$ of $F$. oxysporum. f. sp. niveum have been described in watermelon $(2,6,8,21,27,28)$. The results of this study demonstrated that the four isolates from Maryland belong to a fourth race which is more virulent than race 2. The Maryland isolates showed consistent virulence toward PI-296341-FR, a genotype which is considered resistant to race 2 , in greenhouse and field microplot experiments. The Maryland isolates also exhibited a higher level of virulence toward PI-296341-FR than a race 2 isolate as measured by stem colonization by $F$. oxysporum. f. sp. niveum. All four Maryland isolates were pathogenic on watermelon and nonpathogenic on non-Citrullus hosts examined. This indicated that they were host specific and that their valid formae specialis designation is $F$. oxysporum $\mathrm{f}$. $\mathrm{sp}$. niveum. The Maryland isolates, which were vegetatively compatible with each other, were not compatible to the reference isolates of races 0,1 , or 2 tested, indicating that the Maryland isolates are a different genetic strain of $F$. oxysporum f. sp. niveum than others evaluated here. Based on these results, a fourth race is designated as race 3 of $F$. oxysporum $\mathrm{f}$. sp. niveum following the established numbering sys-

Table 5. Incidence of Fusarium wilt of four differential watermelon genotypes and disease reaction ratings on PI-296341-FR (MD) inoculated with isolates of Fusarium oxysporum f. sp. niveum using the root-dip method in 2008

\begin{tabular}{|c|c|c|c|c|c|c|}
\hline \multirow[b]{2}{*}{ Isolate } & \multirow[b]{2}{*}{ Race } & \multicolumn{4}{|c|}{ Wilt on watermelon genotype $(\%)^{y}$} & \multirow[b]{2}{*}{ Reaction $^{\mathrm{z}}$} \\
\hline & & Sugar Baby & Charleston Gray & Calhoun Gray & PI-296341-FR (MD) & \\
\hline TX-471 & 0 & $63 \mathrm{a}$ & $2 \mathrm{a}$ & $0 \mathrm{a}$ & $0 \mathrm{a}$ & $\mathrm{R}$ \\
\hline ATCC-44293 & 1 & 98 bc & $73 \mathrm{~b}$ & $0 \mathrm{a}$ & $0 \mathrm{a}$ & $\mathrm{R}$ \\
\hline TX-X1D & 2 & $100 \mathrm{c}$ & $100 \mathrm{~d}$ & $95 \mathrm{bc}$ & $0 \mathrm{a}$ & $\mathrm{R}$ \\
\hline F-032-1 & 2 & $100 \mathrm{c}$ & $95 \mathrm{c}$ & $92 \mathrm{bc}$ & $0 \mathrm{a}$ & $\mathrm{R}$ \\
\hline F-100-2 & 2 & $100 \mathrm{c}$ & $100 \mathrm{~d}$ & $98 \mathrm{dc}$ & $2 \mathrm{a}$ & $\mathrm{R}$ \\
\hline F-17B-R-2 & 2 & $95 \mathrm{~b}$ & $95 \mathrm{c}$ & $90 \mathrm{~b}$ & $0 \mathrm{a}$ & $\mathrm{R}$ \\
\hline F-17B-1-10 & 2 & $100 \mathrm{c}$ & $95 \mathrm{c}$ & $97 \mathrm{dc}$ & $0 \mathrm{a}$ & $\mathrm{R}$ \\
\hline MD-ZE085 & 3 & $100 \mathrm{c}$ & $100 \mathrm{~d}$ & $98 \mathrm{dc}$ & $95 \mathrm{~b}$ & $\mathrm{~S}$ \\
\hline MD-ZE125 & 3 & $100 \mathrm{c}$ & $100 \mathrm{~d}$ & $98 \mathrm{dc}$ & $100 \mathrm{~b}$ & $\mathrm{~S}$ \\
\hline MD-ZE622 & 3 & $100 \mathrm{c}$ & $100 \mathrm{~d}$ & $98 \mathrm{dc}$ & $98 \mathrm{~b}$ & $\mathrm{~S}$ \\
\hline MD-ZE632 & 3 & $100 \mathrm{c}$ & $100 \mathrm{~d}$ & $100 \mathrm{~d}$ & $98 \mathrm{~b}$ & $\mathrm{~S}$ \\
\hline
\end{tabular}

y Data were averaged over two experiments of three replicated pots (10 plants/pot) each. Incidence of Fusarium wilt was rated at 4 weeks after inoculation. Means in column followed by the same letter are not significantly different $(P=0.05)$ according to Fisher's protected least significant difference test. Wilt incidence data were arcsine-square root transformed prior to analysis.

${ }^{\mathrm{z}}$ Ratings of disease reaction on PI-296341-FR (MD) were assigned for the isolates based on wilt incidence on the differential genotype, where $\mathrm{R}=$ resistant ( $<33 \%$ wilt) and $\mathrm{S}=$ susceptible ( $\geq 33 \%$ wilt), following the criteria established by Martyn and Bruton (22).

Table 6. Incidence of Fusarium wilt of two differential watermelon genotypes and disease reaction ratings on PI-296341-FR (MD) transplanted in field microplots infested with isolates of Fusarium oxysporum f. sp. niveum

\begin{tabular}{|c|c|c|c|c|c|c|}
\hline \multirow[b]{3}{*}{ Isolate } & \multirow[b]{3}{*}{ Race } & \multicolumn{4}{|c|}{ Wilt on watermelon genotype $(\%)^{y}$} & \multirow[b]{3}{*}{ Reaction $^{\mathrm{z}}$} \\
\hline & & \multicolumn{2}{|c|}{ Experiment 1} & \multicolumn{2}{|c|}{ Experiment 2} & \\
\hline & & Calhoun Gray & PI-296341-FR (MD) & Calhoun Gray & PI-296341-FR (MD) & \\
\hline F-100-2 & 2 & $100 \mathrm{a}$ & $0 \mathrm{a}$ & $95 \mathrm{a}$ & $0 \mathrm{a}$ & $\mathrm{R}$ \\
\hline MD-ZE085 & 3 & $100 \mathrm{a}$ & $90 \mathrm{~b}$ & $95 \mathrm{a}$ & $90 \mathrm{~b}$ & $\mathrm{~S}$ \\
\hline MD-ZE125 & 3 & $100 \mathrm{a}$ & $95 \mathrm{~b}$ & $100 \mathrm{a}$ & $90 \mathrm{~b}$ & $\mathrm{~S}$ \\
\hline
\end{tabular}

${ }^{y}$ Data were the mean of four replicated microplots containing five plants of each of the watermelon genotypes Calhoun Gray and PI-296341-FR (MD). Incidence of Fusarium wilt was rated at 6 weeks after plants were transplanted in $F$. oxysporum f. sp. niveum-infested microplots. Control watermelon plants in noninfested microplots remained healthy and are not presented in the table. Means in a column followed by the same letter are not significantly different $(P=0.05)$ according to Fisher's protected least significant difference test. Wilt incidence data were arcsine-square root transformed prior to analysis.

${ }^{z}$ Ratings of disease reaction on PI-296341-FR (MD) were assigned for the isolates based on mean incidence of Fusarium wilt on the differential genotype over two experiments, where $\mathrm{R}=$ resistant ( $<33 \%$ wilt) and $\mathrm{S}=$ susceptible ( $\geq 33 \%$ wilt), following the criteria established by Martyn and Bruton ( 22 ). 
tem for races of $F$. oxysporum f. sp. niveum (6). The new race 3 was found 37 years after the highly virulent race 2 was first reported by Netzer and Dishon in 1973 (28).

The discovery of race 3 in Maryland is important but not surprising. It may have evolved due to the high selection pressure placed on the pathogen by the intensive cultivation of race-1-resistant watermelon cultivars in the fields where the race 3 isolates were originally collected. The fields had been cropped to watermelon of various cultivars, most of which were race 1 resistant, for many years (up to 22 years), resulting in the highest soil populations of $F$. oxysporum f. sp. niveum among watermelon production fields surveyed (37). These fields also contained the highest ratios of pathogenic to total populations of $F$. oxysporum (more than $80 \%$ of total isolates) and the highest proportions of race 2 (more than $76 \%$ of total isolates) (37). However, the possibility of introduction of race 3 from a foreign source along with infected seed or seedlings or the evolution of race 3 from nonpathogenic $F$. oxysporum cannot be excluded $(20,34)$. The potential origin of races 0,1 , and 2 of $F$. oxysporum f. sp. niveum in the MidAtlantic region has been discussed in a previous study (40).

Difficulties in determining races of $F$. oxysporum f. sp. niveum have been recognized for many years. This is partly due to the fact that the results of pathogenicity tests can be greatly affected by many factors such as inoculum concentration, age of inoculated plants, environmental conditions, inoculation method, and source of differential genotypes $(1,18,23)$. The results of our virulence tests also demonstrated the difficulties in race identification in two aspects First, we observed apparent segregation in the populations of PI296341-FR (FL) or PI-296341-FR (OK) that were used to differentiate race 3 from race 2 in the first two evaluations of this study. In these two tests, inoculations with a race 2 strain (TX-X1D) resulted in a range of 20 to $32 \%$ wilt on either FL or OK populations of PI-296341-FR. This confirmed that the genetics of PI-296341$F R$ are not completely fixed $(12,24,35)$ and that the race-2-susceptible portion of the populations may have increased with the propagation of the PI lines. Second, there is a concern about potential reduction in virulence of the reference race 2 strain (TX-X1D). We observed this during the evaluations conducted in 2002 and 2005. Therefore, it was necessary to include multiple known race 2 reference strains and more sources of the key differential PI-296341-FR for greater precision in the separation of race 3 from race 2 $(17,20,23)$.

Because strains of $F$. oxysporum f. sp. niveum frequently exhibit a continuum in virulence on the differentials $(2,17,21,37)$, quantitative wilt values used to assign isolates to a specific race were not provided in some studies $(1,6,14,17,20)$. Furthermore, the wilt values used in other studies to classify the races have often been inconsistent $(22,23,27,37)$. To standardize the criteria used to distinguish races, based on the results of our current study and previous studies $(9,37)$, we support the use of the system proposed by Martyn and Bruton (22) to characterize disease reactions on the differential genotypes for race determination (Table 1). In this system, a mean wilt incidence of $\geq 33 \%$ was rated as susceptible and $<33 \%$ was rated as resistant. The categories of resistance and susceptibility established in this system also closely followed the significant $(P=0.05)$ separations of percentage wilt in our study and previous studies $(17,37)$. This system has already been used for race determination in some previous studies $(9,37)$. Appropriate disease values that could be used to differentiate races of $F$. oxysporum f. sp. niveum are critical to the studies of biology, epidemiology, and management of Fusarium wilt in watermelon.

The extent of the distribution of the new race in the Mid-Atlantic region has not been investigated but its occurrence in four farms located in two counties in Maryland indicates that it may exist throughout the Mid-Atlantic region. The existence of race 3 represents an additional threat to watermelon production in the region and increases the difficulty of managing Fusarium wilt. Race 2, to which no resistance exists in current watermelon cultivars, is already reported in 8 states $(3,5,10,17,19$, 22,36; A. P. Keinath, personal communication), 6 of which are in the top 10 watermelon production states in the United States. This situation is especially problematic in watermelon production areas such as Maryland and Delaware, where a high percentage of watermelon acreage is triploid (seedless) watermelon. Triploid watermelon cultivars are generally more susceptible to Fusarium wilt than diploid (seeded) cultivars, and almost all currently grown triploid watermelon cultivars (with a few exceptions such as Seedless Sangria and Revolution) are susceptible to race 1 (41). Long-term crop rotation (more than 5 years) and chemical fumigation (not methyl bromide since 2005) may be the best available options for management of Fusarium wilt caused by race 3 . Both control methods could significantly reduce the inoculum levels of the pathogen in soil. However, land availability and economic issues will limit implementation of these two tactics. Other approaches, such as grafted transplants (4), soil amendment (39), or integrated use of multiple methods, may be needed for effective management of Fusarium wilt caused by this new race in watermelon.
LITERATURE CITED

1. Armstrong, G. M., and Armstrong, J. K. 1978 Formae speciales and races of Fusarium oxysporum causing wilts of the Cucurbitaceae. Phytopathology 68:19-28.

2. Bruton, B. D., and Damicone, J. P. 1999 Fusarium wilt of watermelon: Impact of race 2 of Fusarium oxysporum f. sp. niveum on watermelon production in Texas and Oklahoma. Subtrop. Plant Sci. 51:4-9.

3. Bruton, B. D., Fish, W. W., and Langston, D B. 2008. First report of Fusarium wilt caused by Fusarium oxysporum f. sp. niveum race 2 in Georgia watermelons. Plant Dis. 92:983.

4. Bruton, B. D., Fish, W. W., Roberts, W., and Popham, T. W. 2009. The influence of rootstock selection on fruit quality attributes of watermelon. Open Food Sci. J. 3:15-34.

5. Bruton, B. D., Patterson, C. L., and Martyn, R. D. 1988. Fusarium wilt ( $F$. oxysporum f. sp. niveum race 2) of watermelon in Oklahoma. Plant Dis. 72:734.

6. Cirulli, M. 1972. Variation of pathogenicity in Fusarium oxysporum f. sp. niveum and resistance in watermelon cultivars. Pages 491-500 in: Actas III Congr. Un. Fitopatol. Mediterr. Oeiras.

7. Correll, J. C., Klittich, C. J. R, and Leslie, J. F. 1987. Nitrate nonutilizing mutants of Fusarium oxysporum and their use in vegetative compatibility tests. Phytopathology 77:1604 1646.

8. Crall, J. M. 1963. Physiologic specialization in Fusarium oxysporum f. sp. niveum. Phytopathology 53:873.

9. Duan, H.-J., Zhang, C.-Y., Li, X.-H., Guo, X.M., Wang, X.-F., and Ma, Z.-Y. 2007. Identification of physiological races and AFLP analysis of Fusarium oxysporum $\mathrm{f}$. sp. niveum from Hebei province. Sci. Agric. Sin. 40:925-931.

10. Egel, D. S., Harikrishnan, R., and Martyn, R. D. 2005. First report of Fusarium oxysporum $\mathrm{f}$. sp. niveum race 2 as causal agent of Fusarium wilt of watermelon in Indiana. Plant Dis. 89:108

11. Gonzalez-Torres, R., Melero-Vara, J. M., Gomez-Vazquez, J., and Jimenez Diaz, R. M. 1993. The effects of soil solarization and soil fumigation on Fusarium wilt of watermelon grown in plastic houses in south-eastern Spain. Plant Pathol. 42:858-864.

12. Hawkins, L. K., Dane, F., Kubisiak, T. L., Rhodes, B. B., and Jarret, R. L. 2001. Linkage mapping in a watermelon population segregating for Fusarium wilt resistance. J. Am. Soc. Hortic. Sci. 126:344-350.

13. Hopkins, D. L., Lobinske, R. J., and Larkin, R P. 1992. Selection of Fusarium oxysporum $\mathrm{f}$ sp. niveum race 2 in monocultures of watermelon cultivars resistant to Fusarium wilt. Phytopathology 82:290-293.

14. Ioannou, N., and Poullis, C. A. 1991. Fusarium wilt of resistant watermelon cultivars associated with a highly virulent local strain of Fusarium oxysporum f. sp. niveum. Agric. Res. Inst. Tech. Bull. 129, Nicosia, Cyprus.

15. Kim, D. H., Martyn, R. D., and Magill, C. W. 1992. Restriction fragment length polymorphism groups and physical map of mitochondrial DNA from Fusarium oxysporum f. sp. niveum. Phytopathology 82:346-353.

16. Komada, H. 1975. Development of a selective medium for quantitative isolation of Fusarium oxysporum from natural soil. Rev. Plant Prot. Res. 8:114-124.

17. Larkin, R. P., Hopkins, D. L., and Martin, F. N 1990. Vegetative compatibility within Fusa rium oxysporum $\mathrm{f}$. $\mathrm{sp}$. niveum and its relationship to virulence, aggressiveness, and race. Can. J. Microbiol. 36:352-358.

18. Latin, R. X., and Snell, S. J. 1986. Comparison of methods for inoculation of muskmelon with Fusarium oxysporum f. sp. melonis. Plant Dis. 70:297-300. 
19. Martyn, R. D. 1985. An aggressive race of Fusarium oxysporum f. sp. niveum new to the United States. Plant Dis. 69:1007.

20. Martyn, R. D. 1987. Fusarium oxysporum f. sp. niveum race 2: a highly aggressive race new to the United States. Plant Dis. 71:233236.

21. Martyn, R. D. 1996. Fusarium wilt of watermelon. Pages 13-14 in: Compendium of $\mathrm{Cu}$ curbit Diseases. T. A. Zitter, D. L. Hopkins, and C. E. Thomas, eds. American Phytopathological Society Press, St. Paul, MN.

22. Martyn, R. D., and Bruton, B. D. 1989. An initial survey of the United States for races of Fusarium oxysporum f. sp. niveum. HortScience 24:696-698.

23. Martyn, R. D., and McLaughlin, R. J. 1983. Effects of inoculum concentration on the apparent resistance of watermelons to Fusarium oxysporum f. sp. niveum. Plant Dis. 67:493495.

24. Martyn, R. D., and Netzer, D. 1991. Resistance to races 0,1 , and 2 of Fusarium wilt of watermelon in Citrullus sp. PI-296341-FR. HortScience 26:429-432.

25. McKeen, C. D. 1951. Investigation of Fusarium wilt of muskmelons and watermelons in southwestern Ontario. Sci. Agric. 31:413-423.

26. Nelson, P. E., Toussoun, T. A., and Marasas, W. F. O. 1983. Fusarium Species: An Illustrated Manual for Identification. Pennsylvania State University Press, University Park.

27. Netzer, D. 1976. Physiological races and soil population level of Fusarium wilt of water- melon. Phytoparasitica 4:131-136.

28. Netzer, D., and Dishon, I. 1973. Screening for resistance and physiological specialization of Fusarium oxysporum in watermelon and muskmelon. (Abstr. 941) Second Int. Congr. Plant Pathol., Minneapolis, MN.

29. Puhalla, J. E. 1985. Classification of strains of Fusarium oxysporum on the basis of vegetative incompatibility. Can. J. Bot. 63:179-183.

30. Reid, J. 1958. Studies on the fusaria which cause wilt in melons. I. The occurrence and distribution of races of the muskmelon and watermelon fusaria and a historical study of the colonization of muskmelon plants susceptible or resistant to Fusarium wilt. Can. J. Bot. 36:393-410.

31. Risser, G., Banihashemi, Z., and Davis, D. W. 1976. A proposed nomenclature of Fusarium oxysporum f. sp. melonis races and resistance genes in Cucumis melo. Phytopathology 66:1105-1106.

32. Sleeth, B. 1934. Fusarium niveum, the cause of watermelon wilt. W. V. Agric. Exp. Stn. Bull. 257:3-23.

33. Smith, E. F. 1894. The watermelon disease of the South. Proc. Am. Adv. Sci. 43:289-290.

34. Taubenhaus, J. J. 1935. Seeds of watermelons and okra as possible carriers of Fusarium wilt. (Abstr.) Phytopathology 25:969.

35. Zhang, X. P., and Rhodes, B. B. 1993. Inheritance of resistance to races 0,1 , and 2 Fusarium oxysporum $\mathrm{f}$. sp. niveum in watermelon (Citrullus sp. PI 296341). Cucurbit Gene Coop. Rep. 16:77-78
36. Zhou, X. G., and Everts, K. L. 2001. First report of the occurrence of Fusarium oxysporum f. sp. niveum race 2 in commercial watermelon production areas of Maryland and Delaware. Plant Dis. 85:1291.

37. Zhou, X. G., and Everts, K. L. 2003. Races and inoculum density of Fusarium oxysporum f. sp. niveum in commercial watermelon fields in Maryland and Delaware. Plant Dis. 87:692698.

38. Zhou, X. G., and Everts, K. L. 2004. Quantification of root and stem colonization of watermelon by Fusarium oxysporum f. sp. niveum and its use in evaluating resistance. Phytopathology 94:832-841.

39. Zhou, X. G., and Everts, K. L. 2004. Suppression of Fusarium wilt of watermelon by soil amendment with hairy vetch. Plant Dis. 88:1357-1365.

40. Zhou, X. G., and Everts, K. L. 2007. Characterization of a regional population of Fusarium oxysporum f. sp. niveum by race, cross pathogenicity, and vegetative compatibility. Phytopathology 97:461-469.

41. Zhou, X. G., Everts, K. L., and Armentrout, D. K. 2003. Evaluation of seedless (triploid) watermelon cultivars for resistance to Fusarium wilt, 2002. Biol. Cult. Tests (online) 18, V003 DOI:10:1094/BC18.

42. Zhou, X. G., Everts, K. L., and Bruton, B. D. 2006. Race 3, a new race of Fusarium ox ysporum f. sp. niveum, the watermelon Fusarium wilt pathogen. (Abstr.) Phytopathology 96:S130. 